\title{
A INCONGRUÊNCIA ENTRE OS PREDICADOS DA EDUCAÇÃO: OS DESAFIOS DA DOCÊNCIA NO CONTEXTO DA EDUCAÇÃO POPULAR
}

\author{
THE INCONGRUITY BETWEEN THE PREDICATES OF EDUCATION: \\ THE CHALLENGES OF TEACHING IN THE CONTEXT OF POPULAR EDUCATION
}

LA INCONGRUENCIA ENTRE LOS PREDICADOS DE LA EDUCACIÓN: LOS DESAFÍOS DE LA DOCENCIA EN EL CONTEXTO DE LA EDUCACIÓN POPULAR

\author{
Filipi Vieira Amorim ${ }^{1}$ \\ Júlia Guimarães Neves ${ }^{2}$ \\ Bruna Telmo Alvarenga ${ }^{3}$ \\ Vilmar Alves Pereira
}

\begin{abstract}
RESUMO: O ensaio propõe uma reflexão sobre os princípios que orientam a concepção de Educação Popular como prática político-pedagógica. A discussão é um diálogo com estudiosos da Educação Popular que culmina com apontamentos sobre os desafios da docência nessa perspectiva. O artigo está dividido em: i) Primeiras palavras; ii) Traços históricos e conceituais da Educação Popular; iii) Os sentidos da Educação Popular; iv) Os desafios da docência no contexto da Educação Popular; v) Considerações finais. A tese principal é a da infeliz necessidade de adjetivarmos a Educação como forma de demarcarmos um campo político, de resistência e de luta, contra as antinomias que perpassam nosso sistema educacional. Ainda, trata-se de uma postura assumidamente em defesa da ética humana com vistas à igualdade e à justiça social.
\end{abstract}

PALAVRAS-CHAVE: Educação Popular. Docência. Ética.

ABSTRACT: The essay proposes a reflection on the principles that guide the idea of Popular Education as a political-pedagogical practice. The discussion is a dialogue with scholars of Popular Education that culminates with notes on the challenges of the act of teaching in this perspective. The article is divided into i) Forewords; ii) Historical and conceptual traits of Popular Education; iii) The senses of Popular Education; iv) The challenges of teaching in the context of Popular Education; v) Final considerations. The main thesis is the unfortunate necessity of qualifying Education as a way to stake out a political field, of resistance and struggle, against the antinomies that underlie our educational system. Still, it is admittedly a posture in defense of the human ethic with a view to equality and social justice.

KEYWORDS: Popular Education. Teaching. Ethics.

\footnotetext{
${ }^{1}$ Doutorando em Educação Ambiental pelo Programa de Pós-Graduação em Educação Ambiental - PPGEA da Universidade Federal do Rio Grande - FURG. Bolsista da CAPES. E-mail: filipi_amorim@yahoo.com.br.

${ }^{2}$ Mestranda em Educação pelo Programa de Pós-Graduação em Educação - PPGEdu da Universidade Federal do Rio Grande - FURG. Bolsista da FAPERGS. E-mail: juliaaneves@ hotmail.com.

${ }^{3}$ Mestranda em Educação pelo Programa de Pós-Graduação em Educação - PPGEdu da Universidade Federal do Rio Grande - FURG. Bolsista da FAPERGS. E-mail: brunatelmoalvarenga@ gmail.com.

${ }^{4}$ Doutor em Educação pela Universidade Federal do Rio Grande do Sul - UFRGS, Professor e Pesquisador no Instituto de Educação e nos Programas de Pós-Graduação em Educação (PPGEdu) e em Educação Ambiental (PPGEA) da Universidade Federal do Rio Grande - FURG. E-mail: vilmar1972@ gmail.com.

Recebido em: 04/07/2015 - Aprovado em: 22/10/2015.
} 
RESUMEN: Este artículo propone una reflexión sobre los principios que guían la idea de la Educación Popular como una práctica política-pedagógica. El debate es un diálogo con estudiosos de la Educación Popular que culmina con notas sobre los desafíos de la docencia en esta perspectiva. El artículo se estructura en: i) Primeras palabras; ii) Las características históricas y conceptuales de la Educación Popular; iii) Los sentidos de la Educación Popular; iv) Los desafíos de la docencia en el contexto de la Educación Popular; v) Observaciones finales. La tesis principal es la desafortunada necesidad de adjetivarnos a la Educación como una manera de replantear un campo político de resistencias y de lucha contra las paradojas que impregnan nuestro sistema educativo. Aún así, es una actitud abierta en defensa de la ética humana con el fin a la igualdad y la justicia social.

PALABRAS CLAVE: Educación Popular. Docencia. Ética.

\section{PRIMEIRAS PALAVRAS}

"Com a educação presente, o homem não atinge plenamente a finalidade da sua existência."

(Immanuel Kant)

As evidências de que vivemos em meio a desigualdades são maiores a cada dia e refletem a ambivalência das condições materiais disponíveis à existência e manutenção de classes sociais distintas. Como bem discerniu o educador Paulo Freire (1921-1997), a sociedade está cindida entre opressores e oprimidos, predicação que não necessita maiores explicações, pois denota a disparidade e a ideia de que os primeiros dominam e os segundos são dominados. Embora posta, essa realidade não é determinista, mesmo que condicione os modos como cada classe social (econômica, política e cultural) produz sua existência, daí a necessidade de se buscar alternativas que problematizem e que transformem esse cenário em nome da igualdade entre os seres e o fim da exploração humana.

Inverso ao que chamamos de determinista é o condicionante. Este, ao contrário do primeiro, deve ser visto como temporário, pois o sujeito possui, ou possuirá, os atributos que lhe conferem poderes (capacidade de "poder ser", "poder não-ser", "poder fazer", "poder desfazer") para sanar suas necessidades específicas. O determinismo, por sua vez, não é temporário, é permanente. É por isso que o único determinante do homem é o seu "poder" como um dever ser natural e ontológico. Imutavelmente, o homem poderá ser condicionado, porém, jamais determinado.

Obviamente, uma ruptura com o que está posto, ou seja, com os condicionantes, não é tarefa fácil, mas nem por isso podemos negar essa possibilidade. A educação, em um sentido lato, aparece como locus alternativo para desarranjar a estrutura que mantém tal fissura social. É por isso que defendemos a tese de que é necessária uma educação que fuja dos parâmetros que dissociam classes sociais e aprimoram a previsibilidade do futuro desigual nas sociedades humanas como se os sujeitos fossem determinados. Para tanto, neste ensaio, objetivamos pensar a Educação Popular como alçada que mina o território legitimado pelo capitalismo que condiciona os sujeitos a viverem como oprimidos. 
De antemão, afirmamos a Educação Popular como práxis política que tem um compromisso pedagógico para além do sentido stricto da formação para o mercado de trabalho. É sabido que a Educação Popular não é uma nova temática e, por isso mesmo, não queremos inaugurá-la, mas (re)afirmá-la. Esse é um dos motivos pela escolha dos caminhos que seguiremos durante a abordagem do artigo, com ênfase nos saberes necessários à docência da Educação Popular.

Além destas primeiras palavras, nosso ensaio percorrerá, ainda que brevemente, o contexto em que está inserida historicamente a Educação Popular, mostrando seus ideais e interesses, bem como o movimento feito para sua emergência. Depois disso, queremos sugerir elementos que acreditamos indispensáveis ao docente que, junto da Educação Popular e sua concepção de mundo, luta em nome da superação dos condicionantes de opressão, pobreza e subserviência de uma classe em favorecimento de outra. Por fim, apontaremos algumas considerações finais que são provisórias e inacabadas, pois não temos a pretensão de oferecer uma verdade imutável e absoluta - dada nossa crença no inacabamento do ser e na reinvenção constante do mundo.

\title{
2 TRAÇOS HISTÓRICOS E CONCEITUAIS DA EDUCAÇÃO POPULAR
}

\author{
"Educação popular é, em si mesma, um movimento de trabalho \\ pedagógico que se dirige ao povo como um instrumento de \\ conscientização." \\ (Carlos Rodrigues Brandão)
}

O panorama atual da educação é um caleidoscópio de interpretações e compreensões, assim como as críticas em torno da questão do ensino escolar do povo, do poder de opressão e/ou libertação que este possui conforme a forma com que é pensado e praticado como "modelo pedagógico". Nessa esteira, cabe a reflexão sobre o imenso campo de trabalho do educador com a classe popular, já que a Educação Popular deve ser reconhecida como um saber legítimo da comunidade.

Salientar as relações humanas e valorizar o saber gerado nessas relações remete-nos aos ritos de delegação de conhecimento realizados pelos homens do passado longínquo. Desde esse período temos exemplos da construção de conhecimentos e saberes em comunidade, onde todos se ensinavam e aprendiam, onde havia destaque educativo na interrelação mãe e filho, por exemplo, que por olhares, toques e diferentes manifestações sensitivas estabeleciam/estabelecem relações de ensino e aprendizagem mútuas. Infelizmente, no âmbito deste artigo, por questões de síntese, é necessário que façamos um recorte temporal quanto a essa questão. O fato é que com o passar dos anos e, sobretudo, com o desenvolvimento de uma cultura individualista por causa das condições materiais alavancadas pelo capitalismo, houve uma desconsideração desse processo socioeducativo de relações naturais entre as comunidades humanas. Os atuais moldes e parâmetros educacionais do sistema capitalista acabam por deslegitimar não só a partilha dos saberes da comunidade como, igualmente, a Educação Popular, que tem suas bases nesses modos de convivência. 
Procurando compreender esse movimento, Brandão (2006) assinala que entre os sentidos da expressão "Educação Popular" está o processo de reprodução dos saberes das comunidades populares, reconhecendo a distribuição social do conhecimento e do capital cultural equivalentes ao de sabedoria ou cultura popular. Mas, afinal, o que é Educação Popular? Para essa resposta, parece-nos urgente, considerando o reconhecimento e valorização dos saberes oriundos das comunidades populares, retratar o momento em que a educação se distanciou das práticas sociais coletivas em que estava imersa para tornar-se um bem institucionalizado. Para tal distanciamento, na companhia dos escritos de Brandão (2006) em sua obra "O que é Educação Popular?", atribuímos a responsabilidade ao processo de criação das escolas, resultado dos agregados sociais que se tornaram complexos e com oposições de categorias definidas de sujeitos sociais, em que a consequência sofrida pela educação foi a perda de seu sentido como partilhas solidárias, passando a ser um sistema de trocas agenciadas.

Entre algumas das decorrências desse processo está a educação, que se tornou alvo do capitalismo. Este, por intermédio das grandes instituições, unifica, para as suas filiais, o ensino, fazendo com que o saber e o reconhecimento das antigas culturas populares, regionais e locais, sejam desvalorizados. No momento em que a educação se torna propriedade de profissionais especializados, o saber perde o reconhecimento de uma grande parcela de seus autores e as diferentes culturas dos povos passam a ser desconsideradas, refletindo o interesse mesmo da unificação em nome da institucionalização do poder de classe.

Vimos aí aquela dissociação social (econômica, política e cultural) anunciada em nossas primeiras palavras, que nega o conhecimento e o saber da classe popular. Assim surgiu a possibilidade de uma educação que atendesse aos anseios da classe popular, quando se retratou em nosso País a instauração do regime democrático depois do fim da ditadura militar (1964-1985). Essa transição oportunizou a educação escolar como um direito de todos os cidadãos, sendo um dos princípios básicos da sociedade democrática, ou seja, a participação de todos os brasileiros fora dita condição fundamental.

Como referência é necessário destacarmos, uma vez mais, Paulo Freire, que durante cinco décadas foi protagonista na (re) criação da Educação Popular desde o Movimento de Cultura Popular no estado do Recife, na década de 1950, até as experiências com as redes de escolas, datadas a partir de 1980. Nos manuscritos do educador estão vinculadas as condições da classe social com o campo educativo. Na concepção de Freire (2014b) não há dissociabilidade entre esses dois fatores da existência humana, pois são complementares.

É nesse sentido que a Educação Popular proporciona, como um dos princípios orientadores de suas práticas, a participação popular em busca de uma sociedade justa, emancipatória e igualitária. Nas palavras de Purin e Nahmías (2005, p. 129): 
A Educação Popular emergiu em tempos difíceis de perseguição e atropelo aos direitos fundamentais. E é justamente nesse contexto que surgiu a necessidade de trabalhar pela liberdade, de gerar uma consciência coletiva da capacidade transformadora e libertadora que nos permite quebrar as cadeias da opressão.

No Brasil, em meados da década de 1960, os movimentos populares sugiram a partir dos debates sobre a Educação de Adultos. Esta, então, ganhou um aliado para reforçar o direito à educação para os adultos, impulsionando-os a lutar por seus direitos com a concepção orientadora da Educação Popular. Só a partir da década de 1980 é que a Educação de Adultos agrega os jovens como público partícipe de seu movimento, dando origem à Educação de Jovens e Adultos - EJA.

Hoje, com escolas públicas e ensino ofertado a todos os brasileiros, a crítica que se constrói gira em torno do modo com que essas instituições se consolidaram e vêm fazendo tal oferta. Por isso, questionamo-nos: até que ponto essa oferta se configurou democrática e indivisivel?

Buscando encontrar algumas respostas para tais indagações, partindo desse breve panorama sobre os traços históricos e conceituais da Educação Popular, entraremos, agora, na discussão que abarca os objetivos e os ideais dela. É importante salientar que não buscamos encerrar a problematização no que discutimos aqui, o que queremos é oportunizar uma reflexão que problematiza o cenário educacional e pedagógico brasileiro.

\section{OS SENTIDOS DA EDUCAÇÃO POPULAR}

"Conscientizar é dar consciência do que é o homem - consciência de si, do que é o mundo, do que são os outros homens."

(Luiz Eduardo Wanderley)

Assumidas as diferenças entre classes sociais, o processo histórico da Educação Popular passou a reivindicar a necessidade de um trabalho diferente com a classe popular, sobretudo por reconhecer que a educação institucionalizada pelo regime democrático brasileiro não era tão "democrático" como se pretendia. Foi a partir disso que educadores e educadoras deram ouvidos às emergências materiais dos oprimidos - a classe popular e trabalhadora - e identificaram necessidades diferentes entre esses sujeitos, principalmente entre os trabalhadores. Com isso foi possível afirmar que a educação não era capaz de igualar oportunidades, de promover melhorias na qualidade de vida, de construir transformações, de assegurar condições de acesso ao trabalho e à vida social (econômica, política e cultural), tal como ocorria nas classes opressoras e proprietárias dos modos de produção.

A educação que se tinha era extensiva à classe popular e não modificou as condições materiais para o público em questão (a classe popular), ao ponto de diminuir o "vazio cultural" existente entre as diferentes classes sociais. Em contrapartida, a educação ajudava a fortalecer o sentimento de distância e abismo entre tais classes. O ambiente escolar, da forma como se configurava na maioria das escolas, constituía-se como um sistema reprodutor da 
desigualdade, resultando em caminhos de oportunidades e de vida, indiscutivelmente, desiguais.

Mesmo que nessa reconstituição histórica nossos verbos estejam conjugados no passado, não temos uma transformação do status quo, mas temos um campo de luta política delimitado pela Educação Popular. Foi com os movimentos populares que nasceu a discussão de uma educação que atendesse, efetivamente, as necessidades do povo, que ampliasse a relação entre Estado, Sociedade e Educação com a classe popular. Destarte, tivemos o reconhecimento de que há uma educação com elementos que o povo cria, com a justificativa de que para haver uma transformação popular e social é necessário que o povo elabore o seu próprio saber. Esse saber formado, compartilhado e transformado pela classe popular, é a ferramenta de enfrentamento contra a desigualdade e a oportunidade de se ter nas mãos a possibilidade de libertação humana. Nesse sentido, é importante sustentarmos o princípio de que o conceito de liberdade, caro à Educação Popular, relaciona-se com a necessidade ontológica do ser mais (FREIRE, 2014a). Significa que, para garantir a libertação da classe trabalhadora, não se trata de uma inversão em que os oprimidos passam a ser os opressores: a liberdade é a necessidade de uma libertação universal que legitime o fim da exploração do homem pelo homem - como afirmaremos algures.

Portanto, falar de uma Educação Popular é (re) conhecer a produção de um conhecimento coletivo nas relações entre educadores e sujeitos populares, tanto em suas experiências intercambiáveis quanto na partilha de vivências; no desenvolvimento de relações de solidariedade e de uma educação pautada no caráter participativo; na reflexão e na conscientização social dos direitos iguais. Assim como o fez Brandão (2006), é possível assinalarmos dois grandes sentidos da expressão Educação Popular, ainda como tentativa de resposta à pergunta lançada anteriormente: i) Educação Popular como democratização do saber escolar; ii) como trabalho de libertação por meio da educação.

Com tais características descritas, a educação encontra seu significado transformado, pois é Educação Popular - não apenas pelo trabalho dirigido à classe de trabalhadores e excluídos da escola, mas por possuir um caráter de criação - no sentido de que ela ensina, expõe e oportuniza o reconhecimento dos saberes que desde já estão no cotidiano dos sujeitos populares. Assim, a Educação Popular se opõe ao modelo pedagógico neoliberal por dar validade aos saberes populares e por possibilitar que esses saberes prévios se entrelacem com saberes novos, sem que os anteriores sejam deixados de lado ou julgados como desnecessários.

Logo, não podemos deixar de citar a tendência inculcada nos oprimidos de legitimarem os opressores como os detentores dos saberes e fazeres verdadeiros, sobretudo os oprimidos da chamada "classe média" (FREIRE, 2014b). Essa é outra luta genuína da Educação Popular, que quer desmitificar a incapacidade do oprimido frente aos desafios cotidianos do viver, a tendência à penalização individual, à naturalização da ideia de destino fadado à permanência nos espaços precarizados (tal como uma vida guiada por um \begin{tabular}{l|l|l|l|l|l|l} 
(C) ETD - Educ. Temat. Digit. & Campinas, SP & v.17 & n.3 & p. 502-513 & set./dez.2015 & ISSN 1676-2592
\end{tabular} 
determinismo oculto) e à autoimagem de inferioridade.

A partir dessas considerações convidamos nossos interlocutores a refletirem sobre a docência no contexto primordialmente popular, comunitário e coletivo. Destacamos que é fundamental compreender o papel do docente nessa (re)configuração pedagógica, pois o papel social do educador e da educadora popular é "ver os educandos e as educandas em suas trajetórias não apenas escolares, mas também de vida, na sua condição de sujeitos sociais, culturais, de direitos totais" (ARROYO, 2001, p. 121). É essa a discussão que dará continuidade ao nosso ensaio.

\title{
4 OS DESAFIOS DA DOCÊNCIA NO CONTEXTO DA EDUCAÇÃO POPULAR
}

\begin{abstract}
As discussões, debates e problematizações da realidade vivida pelas classes populares precisam ser o ponto de partida de uma nova educação, capaz de participar da criação de uma nova cultura.
\end{abstract}

(Carlos Rodrigues Brandão)

Não temos dúvidas de que a educação tradicional não traz consigo os elementos que julgamos necessários à Educação Popular. Do mesmo modo, é lamentável que a educação tenha que ser adjetivada (como popular, tradicional, ambiental, escolar, do campo, etc.), mas as condições materiais nas quais estamos inseridos nos impedem de não a predicar. Entre a educação tradicional e a Educação Popular, para não citar outros exemplos, existem incongruências. Rapidamente, podemos afirmar que a primeira oprime a segunda, negando a importância de seus conhecimentos e saberes; a segunda surge como denúncia da existência daquela primeira na qualidade de educação alheia ao povo, isto é, a Educação Popular anuncia outros sentidos ao processo educativo.

Em nossa compreensão, essa rechaça ocorre por causa do processo de globalização do capitalismo que quer universalizar a cultura do presenteísmo, do individualismo, do mecanicismo e do consumismo. A relação da (i) educação tradicional com a história também difere da compreensão que emana dos poros da (ii) Educação Popular: (i) no primeiro caso, a história é determinante na constituição dos sujeitos sociais; (ii) já para o segundo caso, a história condiciona, mas não determina - o sujeito social é um ser inacabado (FREIRE, 2014a).

Consideramos que afirmar uma incongruência entre educação tradicional e Educação Popular é assumir que a pedagogia é um campo político, de luta, de disputa, de interesses. Assim, opomo-nos ao saber que afirma uma imutabilidade das condições materiais de existência das comunidades humanas. É daí que alcançamos a necessidade de conhecermos os desafios da docência no contexto da Educação Popular, visto que por si mesma a educação tradicional tem se legitimado. Isso decorre do fato de que há uma (re)produção constante daquilo que está posto: o capitalismo e a sociedade de classes. Vale lembrar que o objetivo da 
Educação Popular não é uma inversão que transporte os sujeitos de um polo ao outro, que passe os oprimidos para a condição de opressores, tampouco o contrário. O papel da Educação Popular é promover e impulsionar a ruptura com a sociedade de classes em nome da libertação de opressores e oprimidos (FREIRE, 2014b).

Nesse sentido, o papel do docente é de mediador da prática educativa com uma ação participativa e dialógica do processo em questão. As partilhas de conhecimentos proporcionam a construção de novos conhecimentos que surgem complementando as epistemologias que permeiam o campo da educação, do mundo e das relações sociais. Com isso, Paludo (2001, p. 95) destaca que "[...] todo educador popular deve ter, na relação com as classes populares, uma postura pedagógica. O núcleo articulador desta postura é a ação reflexiva, mediada pelo seu compromisso e pela participação e diálogo de todos os envolvidos".

Em uma relação pautada pelo diálogo, o educador popular, na medida em que educa, também é educado. Há, nessa relação, compartilhamento de conhecimentos e de saberes, não há um saber mais ou um saber menos, mas a existência de saberes diferentes e complementares. Não há o professor como o detentor dos saberes, mas o educador que é educado com os educandos. É por isso que a Educação Popular propõe que saberes dialogados de forma participativa, crítica, libertadora e conscientizadora orientem o processo de aprendizagem no qual estão imersos educadores e educandos (FREIRE, 2014b). Assumindo essa perspectiva desde sua radicalidade, vemos que a educação verdadeira só existe onde há diálogo aberto e respeitoso, do contrário não há processo de ensinoaprendizagem e aprendizagem-ensino mútuos; não existe interação legítima no silêncio obscuro do autoritarismo docente. O desafio, na verdade, é ainda maior: o educador popular deve auscultar para além da voz dos estudantes; tem de estar aberto ao mundo que os rodeia e à realidade que os condiciona e, ainda, educadora e educador popular têm de deixar claro que não há determinante social (econômico, político e cultural).

Na possibilidade da construção de uma educação democrática, educadores e educandos populares fazem da prática pedagógica um espaço de reflexão crítica da sociedade, de análise quanto ao teor de uma sociedade de classes, denunciando o modelo social dominante e anunciando a viabilidade de uma sociedade justa e igualitária. Do mesmo modo, como espaço que denuncia e anuncia a sociedade que condiciona, a Educação Popular promove a escuta da realidade em que os sujeitos populares refletem sobre a reprodução das forças de trabalho que os mantêm à margem da sociedade e em posição subserviente.

É aqui que reside a condição humana de sobrevivência, uma vez que esse "sobreviver" apenas garante a vida, mas não é viver... é a manutenção das condições mínimas para a exploração do trabalho humano, é a exploração do homem pelo homem. O termo "sobreviver" também não garante que "sobre-vida" seja algo mais do que o simples viver. $\mathrm{Na}$ verdade, o sentido do "sobre-viver", quando se está sob a ótica da determinação capitalista, está mais relacionado com condições de "sub-vida" do que de "sobre-vida". Esse "sobre- 
viver" é a condição oferecida pelo mercado de trabalho cada vez mais excludente e seletivo, tratando os seres humanos como mercadorias descartáveis e substituíveis.

Engajados em movimento de reivindicação por condições de vida dignas, por políticas educacionais de acesso e permanência de maneira igualitária para todos, a Educação Popular anuncia novas possibilidades como forma de a classe popular movimentar-se politicamente por entre os espaços sociais (econômicos, políticos e culturais). Quando o povo se torna "povo político" (PALUDO, 2006), é que há luta no intento de assegurar que amplos setores sociais possam intervir ativamente nos rumos da sociedade. Intervenção que se torna possível por meio da participação política de cidadãos preocupados com a coisa pública, informados e produtores de fatos políticos. É com este compromisso e partícipe na luta com os sujeitos populares que o educador popular encontra o embasamento ideológico, político e intelectual de sua prática pedagógica

Por isso, os educadores e educadoras populares devem estar, necessariamente, comprometidos com a totalidade da formação humana. Isso significa dizer que suas preocupações estão para além dos endereçamentos fixos e simplistas no qual se admite uma educação, exclusivamente, para o mercado de trabalho. É nesse sentido que a Educação Popular não se deixa ser objetivada por uma sociedade que alimenta a competição e o individualismo. Por isso, enfatizamos uma vez mais, o posicionamento dos educadores e educadoras populares está na contramão das aspirações da educação tradicional promovida pela classe opressora.

Nisso tudo trilha a consideração necessária sobre a condição ontológica do educador e da educadora populares. O ser ultrapassa a condição primariamente profissional, pois não significa apenas estar docente. Na busca do ser mais, o ser transcende o sentido restrito do estar em sala de aula ou nas instâncias educacionais, por isso reflete para além do significado stricto que garante uma condição empregatícia:

\footnotetext{
Somos, não apenas exercemos a função docente. Poucos trabalhos e posições sociais podem usar o verbo ser de maneira tão apropriada. Poucos trabalhos se identificam tanto com a totalidade da vida pessoal. Os tempos da escola invadem todos os outros tempos. [...] ser professoras e professores faz parte de nossa vida pessoal. É o outro em nós (ARROYO, 2008, p. 27).
}

Imbuídos dessa compreensão, sujeitos populares, educadores e educandos, reivindicam politicamente direitos sociais por meio da construção de uma cultura de participação política solidária. Nessa reivindicação está a luta, entre outras, pela defesa da escola pública e da educação para todos. Falar em direito à educação é admitir a garantia capaz de oportunizar a vivência da cidadania. Imersa nesse direito está a luta pela escola pública como mecanismo de reprodução do saber que parte dos trabalhadores, reconhecendo que a educação constitui um direito social valorizado no meio popular e pelos educadores comprometidos. 
Orientados pelos princípios da Educação Popular, buscamos, sobretudo, a construção de espaços educativos pautados na reflexão, na tomada de consciência e no fomento à participação política que, como complemento desse ciclo, inaugura a construção da cidadania. Na qualidade de direito maior, a cidadania é aqui entendida como garantia e ampliação dos direitos e deveres políticos e sociais para que todos os sujeitos, de forma igualitária e livre, possam usufruir dos benefícios materiais e sociais disponíveis à humanidade. Não há cidadania sem a possibilidade de intervenção da classe popular nos destinos sociais, não há cidadania diante de um futuro vedado. Daí que afirmamos: a Educação Popular não é uma modalidade entre tantas outras, é uma forma de ser e conceber o mundo.

\section{CONSIDERAÇÕES FINAIS}

"Cabe a nós fazer a história e sermos feitos e refeitos por ela."

(Paulo Freire)

Nesse viés que assumimos, acreditamos que não é possível mascarar a estrutura social (econômica, política e cultura) na qual estamos imersos: vivemos em um contexto de desigualdade e de injustiças sociais. Depois de nossos apontamentos, estamos no ponto de chegada da discussão, mas, conscientes, sabemos que o percurso não acaba aqui, que a estrada é longa e que a luta não será fácil. Os desafios que transpassam a Educação Popular estão diariamente postos à prova. O sistema capitalista, responsável por essas antinomias que nos levam ao encontro de adjetivos que demarcam nossa luta política e ideológica em nome da Educação, se reinventa a todo momento em nome da manutenção da opressão e da exploração da vida humana. Embora seja sabido, e não queremos (como diz o dito popular) "chover no molhado", é necessário afirmar, mais uma vez, que as desigualdades sociais estão aí e não podem ser naturalizadas. Entre outros, talvez esse seja um dos maiores desafios do educador e da educadora popular: desmitificar o aparato ideológico da cultura do opressor que levianamente oferece uma história determinista aos espoliados do mundo.

Nossa crítica é contra a frivolidade do capitalismo, contra o egoísmo que acentua a ganância impulsionada pelo individualismo da sociedade de classes. Enquanto houver esse abismo que repulsa qualquer princípio altruísta como valor humano, haverá, em nome da minoria esmagadora, um divisor desigual e violento de comunidades humanas. Com isso só se acentuam o sofrimento e as amálgamas da vida àqueles que são a grande maioria oprimida. O que determina essa disparidade são fatores de ordem econômica, política e cultural. Essa realidade não é alheia à Educação e neste sentido é que foram refletidos os desafios da docência em um ambiente de desigualdades.

$\mathrm{Na}$ acusação dessa realidade, a Educação Popular, como práxis política, propõe pela reflexão, da conscientização, do diálogo e da ação, arranhar a lógica perversa e desigual da qual se nutre o sistema capitalista. Com base na categoria diálogo, que o educador Paulo Freire propõe como meio de transformação social, Fleuri (1989, p. 59) aponta que: 
O diálogo e a participação entre as pessoas ocorrem a partir e em função dos problemas que se enfrentam em conjunto. Os problemas que emergem da vida e da prática social se tornam, portanto, o objetivo principal de conhecimento, o conteúdo próprio da prática educacional. Na busca de compreender e resolver os problemas que surgem da própria prática, as pessoas discutem, trocam opiniões e experiências e buscam informações e elaboram novos conhecimentos.

Imersos em uma mudança de paradigma, educadores e sujeitos populares relacionamse por meio do diálogo entre pessoas que, a partir de suas singularidades e diferenças, compartilham a vontade e o interesse de transformar a realidade em função de visões de futuro emancipadoras. Para além dos processos cognitivos envolvidos com o ensino e a aprendizagem, educadores e educandos, encharcados de esperança e agarrados nas memórias individuais e coletivas produtoras de saberes e na luta pelo desenvolvimento social, traduzido na igualdade de direitos, fazem da Educação Popular sua especificidade como uma realidade social e pedagógica.

Nessa realidade, um de seus inerentes constituintes é a sensibilidade em relação aos contextos políticos, sociais e culturais nos quais atuam. Sua razão, como Educação Popular, existe no questionamento e resistência às realidades injustas e em sua articulação com as lutas e movimentos populares. Nesta esteira, educadores e educadoras, em comunhão com os sujeitos populares, concebem-se como um coletivo pedagógico de autores sociais que escrevem sua própria história. Educadores e educadoras populares, na reflexão de seu que fazer pedagógico, não se perguntam somente pelo “como?", em um sentido metodológico, mas também pelo "por quê?", "para quê?" e "para quem?", pelo “onde?"; e pelo "com quem?" constroem suas práticas.

Os sentidos da nossa adjetivada Educação Popular tem intencionalidades de potencializar o caráter emancipador da vida humana a partir de práticas que não se restringem a exposição de conteúdos críticos, mas na incorporação de critérios para a formação de pensamentos e subjetividades críticas. Carrillo (2013), ajuda-nos a pensar sobre esses critérios ao apontar a atitude problematizadora dos educadores populares na existência de uma capacidade de assombro, disposição e vontade de pensar na perspectiva crítica; em "colocar-se frente a realidade", posicionando-se frente aos contextos, às circunstancias históricas que desafiam e condicionam. É assim que educadores e educadoras populares posicionam-se, então, ética e politicamente no reconhecimento dos condicionamentos e limites impostos pela realidade, mas também, acreditam na possibilidade e capacidade para fazê-lo, com outros, alicerçados em sonhos e utopias partilhadas. 


\section{REFERÊNCIAS}

ARROYO, Miguel Gonzalez. Ofício de mestre: imagens e auto-imagens. Petrópolis: Vozes, 2008.

ARROYO, Miguel Gonzalez. Paulo Freire e o projeto popular para o Brasil. In: SOUZA, Ana Inês (Org.). Paulo Freire. Vida e obra. São Paulo: Expressão Popular, 2001.

ARROYO, Miguel Gonzalez. Escola como espaço público: exigências humanas. Revista de Educação AEC, Brasília, DF, v. 30, n. 121, p. 118-123. out./dez. 2001. ISSN 0104-0537.

BRANDÃO, Carlos Rodrigues. O que é educação popular? São Paulo: Brasiliense, 2006.

CARRILLO, Alfonso Torres. A Educação Popular como prática política e pedagógica emancipadora. In: STRECK, Danilo; ESTEBAN, Maria Teresa. (Org.). Educação popular: lugar de construção social coletiva. Petrópolis: Vozes, 2013.

FREIRE, Paulo. Pedagogia da autonomia: saberes necessários à pratica educativa. Rio de Janeiro: Paz e Terra, 2014a.

FREIRE, Paulo. Pedagogia do oprimido. Rio de Janeiro: Paz e Terra, 2014b.

FREIRE, Paulo. Educação como prática da liberdade. Rio de Janeiro: Paz e Terra, 1967.

FLEURI, Reinaldo Matias. Educar para quê? - Contra o autoritarismo da relação pedagógica na escola. São Paulo: Cortez, 1989.

PALUDO, Conceição. Educação popular em busca de alternativas: uma leitura desde o campo democrático e popular. Porto Alegre: Tomo Editorial, 2001.

PALUDO, Conceição. Educação Popular - Dialogando com Redes Latino-Americanas (2002-2003). In: PONTUAL, Pedro Pontual; IRELAND, Timothy (Org.). Educação popular na América Latina: diálogos e perspectivas. Brasília, DF: Ministério da Educação: UNESCO, 2006.

\section{Como citar este documento:}

NEVES, Júlia Guimarães et al. A incongruência entre os predicados da educação: os desafios da docência no contexto da educação popular. ETD - Educação Temática Digital, Campinas, SP, v. 17, n. 3, nov. 2015. ISSN 1676-2592. Disponível em: 〈http://periodicos.sbu.unicamp.br/ojs/index.php/etd/article/view/8638206>. Acesso em: 15 dez. 2015. 